\title{
The etiology of narcolepsy
}

\begin{abstract}
Narcolepsy is a neurological disorder that affects the nervous system leading to the loss of the brain's ability to regulate sleep-wake cycles. It is characterized by diurnal somnolence and episodes of short duration sleep. Symptoms include repeated daytime sleepiness, similar to how people who do not have narcolepsy feel after 24-48hours of sleep deprivation, as well as disturbed sleep, which often is confused with insomnia. Another common symptom of narcolepsy is cataplexy, a sudden and transient episode of muscle weakness accompanied by full conscious awareness, frequently triggered by emotions such as laughing, crying, terror, etc. affecting almost $70 \%$ of people who have narcolepsy. Recent laboratories research on hypocretins (oroxins) has led to a greater understanding of this debilitating condition. The goal of this minireview is to describe briefly the etiology of narcolepsy.
\end{abstract}

Keywords: narcolepsy, etiology, hypocretins, cataplexy, deprivation, sleepiness, somnolence, symptoms, neurologist, hypothalamus, hypothesis, orexin, dynorphin, narcoleptics, hormone
Volume 4 Issue 2 - 2017

\author{
Farah Hamad Farah \\ Department of pharmaceutics, Ajman University, UAE
}

Correspondence: Farah Hamad Farah, Department of Pharmaceutics, College of Pharmacy and Health Sciences, Ajman University, UAE, Tel 97167056200, Email f.hamad@ajman.ac.ae

Received: February 16, 2017| Published: February 17, 2017

\section{Short communication}

Toward the end of World War I, an epidemic of encephalitis swept across Europe. In many patients, this caused crushing sleepiness, and the Austrian neurologist Constantin von Economo ${ }^{1}$ found that these patients usually had inflammation and injury to the posterior hypothalamus. He went on to speculate that the sleepiness of narcolepsy might be caused by injury to this region, but for decades this hypothesis could not be tested as so little was understood about the cells and functions of the hypothalamus. In 1998, two labs independently discovered a pair of hypothalamic neuropeptides termed orexin-A and -B (or hypocretin 1 and 2) and their receptors (OX1 and OX2). ${ }^{2,3}$ The orexins have since been demonstrated to play essential roles in maintaining wakefulness and regulating transitions between sleep and wake. ${ }^{4-8}$ The following year, another pair of research teams found compelling evidence that narcolepsy could be caused by a loss of orexin signaling. Masashi Yanagisawa's group produced an orexin ligand knockout mouse with sleepiness and cataplexy strikingly similar to human narcolepsy. ${ }^{4}$ Simultaneously, Emmanuel Mignot's group demonstrated that canine narcolepsy resulted from a mutated orexin receptor. ${ }^{9}$ The definitive link between narcolepsy and orexin followed when researchers demonstrated a lack of orexin peptides in the hypothalamic and CSF of narcolepsy patients. ${ }^{10-12}$ Further research has demonstrated that nearly $90 \%$ of the orexin-producing neurons are lost in human narcolepsy with cataplexy. The endogenous opiate dynorphin and NARP (a protein involved in glutamate signaling) are also produced by the orexin neurons, and both of these markers are absent in the lateral hypothalamus of patients with narcolepsy. ${ }^{13,14}$ This cell loss seems highly selective, as neurons producing melaninconcentrating hormone, which are intermingled with the orexin neurons, seem completely unaffected. ${ }^{10,11}$ Collectively, these studies provide strong evidence that some process selectively destroys the orexin neurons. These studies focused on patients that have narcolepsy with cataplexy, yet much less is understood about the neuropathology of narcolepsy without cataplexy. This type of narcolepsy affects approximately half of all patients with narcolepsy, and the severity of symptoms is often less than in patients with cataplexy. ${ }^{15}$ Though little is known about the underlying neuropathology, narcolepsy without cataplexy may simply be caused by less severe injury to the orexin neurons, ${ }^{16}$ resulting in mainly sleepiness and a small reduction in CSF orexin level..$^{12,17}$ Mild to moderate loss of the orexin neurons has also been demonstrated in Parkinson's disease ${ }^{18}$ and traumatic brain injury, ${ }^{19}$ disorders that often produce sleepiness but no cataplexy. In addition to controlling sleep/wake states, the orexin neurons also regulate metabolism, feeding, reward, and autonomic tone, resulting in additional symptoms. ${ }^{20-22}$

Many studies have indicated an association between narcolepsy and obesity, where it has been demonstrated that narcoleptics were more likely to be overweight compared to non-narcoleptics s. ${ }^{23-25}$ For example, weight gain is common at the onset of narcolepsy, especially in children, perhaps from a reduction in basal metabolic rate. ${ }^{26,27}$

The National Institute of Neurological Disorders and Stroke (NINDS) sponsored researchers are conducting studies devoted to further clarifying the wide range of genetic factors-both HLA genes and non-HLA genes-that may cause narcolepsy. ${ }^{28}$ A greater understanding of the complex genetic and biochemical bases of narcolepsy will eventually lead to the formulation of new therapies to control symptoms and may lead to a cure. Researchers are also investigating the modes of action of wake-promoting compounds to widen the range of available therapeutic options. ${ }^{29}$ Abnormal immunological processes may be an important element in the cause of narcolepsy. NINDS-sponsored scientists have demonstrated the presence of unusual, possibly pathological, forms of immunological activity in narcolepsy. Further, Strep throat is now suggested to be involved as a trigger in some predisposed individuals. ${ }^{30}$ These researchers are now investigating whether drugs that suppress immunological processes may interrupt the development of narcolepsy. ${ }^{30}$ A more comprehensive understanding of the complex biology of sleep will undoubtedly further clarify the pathological processes that underlie narcolepsy and other sleep disorders. Future neurobiology research shall reveal more facts about the etiology of narcolepsy.

\section{Acknowledgments}

None.

\section{Conflicts of interest}

Author declares there are no conflicts of interest.

\section{Funding}

None. 


\section{References}

1. Economo Von K. Encephalitis lethargica. Wiener klinische Wochenschrift. 2017;30:581-585.

2. de Lecea L, Criado J, Rivera S, et al. Endogenous protein kinase A inhibitor $(\mathrm{PKI} \alpha)$ modulates synaptic activity. Journal of Neuroscience Research. 1998;53:269-278.

3. Sakurai T, Amemiya A, Ishii M, et al. Orexins and orexin receptors: a family of hypothalamic neuropeptides and $\mathrm{G}$ protein-coupled receptors that regulate feeding behavior. Cell. 1998;92(4):573-585.

4. Chemelli RM, Willie JT, Sinton CM, et al. Narcolepsy in orexin knockout mice: molecular genetics of sleep regulation. Cell. 1999;98(4):437-451.

5. Mochizuki H, Terao Y, Okabe S, et al. Effects of motor cortical stimulation on the excitability of contralateral motor and sensory cortices. Exp Brain Res. 2004;158(4):519-526.

6. Adamantidis AR, Zhang F, Aravanis AM, et al. Neural substrates of awakening probed with optogenetic control of hypocretin neurons. Nature. 2007;450(7168):420-424.

7. Diniz Behn CG, Booth V. Simulating Microinjection Experiments in a Novel Model of the Rat Sleep-Wake Regulatory Network. $J$ Neurophysiol. 2010;103(4):1937-1953.

8. Sasaki J, Kim HS, Xu J. Religion and well-being: an analysis of an oxytocin receptor polymorphism (OXTR) and culture. Journal of CrossCultural Psychology. 2011;42(8):1394-1405.

9. Lin L, Faraco J, Li R, et al. The sleep disorder canine narcolepsy is caused by a mutation in the hypocretin (orexin) receptor 2 gene. Cell. 1999;98(3):365-376.

10. Peyron C, Faraco J, Rogers W, et al. A mutation in a case of early onset narcolepsy and a generalized absence of hypocretin peptides in human narcoleptic brains. Nat Med. 2000;6(9):991-997.

11. Thannickal TC, Moore RY, Nienhuis R, et al. Reduced number of hypocretin neurons in human narcolepsy. Neuron. 2000;27(3):469-474.

12. Mignot E, Lammers GJ, Ripley B, et al. The role of cerebrospinal fluid hypocretin measurement in the diagnosis of narcolepsy and other hypersomnias. Arch Neurol. 2002;59(10):1553-1562.

13. Blouin AM, Thannickal TC, Worley PF, et al. Narp immunostaining of human hypocretin (orexin) neurons: loss in narcolepsy. Neurology. 2005;65(8):1189-1192.

14. Crocker A, España RA, Papadopoulou M, et al. Concomitant loss of dynorphin, NARP, and orexin in narcolepsy. Neurology. 2005;65(8):1184-1188.
15. Sasai T, Inoue Y, Komada Y, et al. Comparison of clinical characteristics among narcolepsy with and without cataplexy and idiopathic hypersomnia without long sleep time, focusing on HLA-DRB1(*)1501/ DQB1(*)0602 finding. Sleep Med. 2009;10:961-966.

16. Thannickal TC, Nienhuis R, Siegel JM. Localized loss of hypocretin (orexin) cells in narcolepsy without cataplexy. Sleep. 2009;32(8):993-998.

17. Andlauer O, Moore H, Hong SC, et al. Predictors of hypocretin (orexin) deficiency in narcolepsy without cataplexy. Sleep. 2012;35(9):1247-1255.

18. Fronczek R, Baumann CR, Lammers GJ, et al. Hypocretin/orexin disturbances in neurological disorders. Sleep Med Rev. 2009;13(1):9-22.

19. Baumann CR, Bassetti CL, Valko PO, et al. Loss of hypocretin (orexin) neurons with traumatic brain injury. Ann Neurol. 2009;66(4):555-559.

20. Aston-Jones G, Smith RJ, Sartor GC, et al. Lateral hypothalamic orexin/ hypocretin neurons: a role in reward-seeking and addiction. Brain Res. 2010;1314:74-90.

21. Cason AM, Smith RJ, Tahsili-Fahadan P, et al. Role of orexin/hypocretin in reward-seeking and addiction: implications for obesity. Physiol Behav. 2010;100(5):419-428.

22. Dimitrova A, Fronczek R, Van der Ploeg J, et al. Reward-seeking behavior in human narcolepsy. J Clin Sleep Med. 2011;7(3):293-300.

23. Bell IR, Guilleminault C, Dement WC. Questionnaire survey of eating habits of narcoleptics versus controls (abstract). Sleep Res. 1975;4:208.

24. Bell IR, Hawley CD, Guilleminault C, et al. Diet and symptom histories in food allergics versus narcoleptics and normals (abstract). Sleep Res. 1976;5:155.

25. Bell IR. Diet histories in narcolepsy. Adv Sleep Res. 1976;3:221-227.

26. Plazzi G, Parmeggiani A, Mignot E, et al. Narcolepsy-cataplexy associated with precocious puberty. Neurology. 2006;66(10):1577-1579.

27. Sonka K, Kemlink D, Busková J, et al. Obesity accompanies narcolepsy with cataplexy but not narcolepsy without cataplexy. Neuro Endocrinol Lett . 2010;31(5):631-634.

28. http://www.nhlbi.nih.gov/about/ncsdr/index.htm

29. Sakai N, Nishino S. Encyclopedia of Sleep. 2013. p.627-633.

30. https://www.ninds.nih.gov/Disorders/Patient-Caregiver-Education/ Fact-Sheets/Narcolepsy-Fact-Sheet 